\title{
Insulation Characteristics of Sisal Fibre/Epoxy Composites
}

\author{
A. Shalwan, ${ }^{1}$ M. Alajmi, ${ }^{1}$ and A. Alajmi ${ }^{2}$ \\ ${ }^{1}$ Manufacturing Engineering Technology Department, College of Technological Studies, \\ Public Authority for Applied Education and Training, 13092 Kuwait City, Kuwait \\ ${ }^{2}$ Automotive and Marine Technology Department, College of Technological Studies, \\ Public Authority for Applied Education and Training, 13092 Kuwait City, Kuwait \\ Correspondence should be addressed to A. Shalwan; ama.alajmil@paaet.edu.kw
}

Received 15 October 2017; Revised 29 November 2017; Accepted 5 December 2017; Published 25 December 2017

Academic Editor: Yiqi Yang

Copyright (C) 2017 A. Shalwan et al. This is an open access article distributed under the Creative Commons Attribution License, which permits unrestricted use, distribution, and reproduction in any medium, provided the original work is properly cited.

Using natural fibres in civil engineering is the aim of many industrial and academics sectors to overcome the impact of synthetic fibres on environments. One of the potential applications of natural fibres composites is to be implemented in insulation components. Thermal behaviour of polymer composites based on natural fibres is recent ongoing research. In this article, thermal characteristics of sisal fibre reinforced epoxy composites are evaluated for treated and untreated fibres considering different volume fractions of $0-30 \%$. The results revealed that the increase in the fibre volume fraction increased the insulation performance of the composites for both treated and untreated fibres. More than $200 \%$ insulation rate was achieved at the volume fraction of $20 \%$ of treated sisal fibres. Untreated fibres showed about $400 \%$ insulation rate; however, it is not recommended to use untreated fibres from mechanical point of view. The results indicated that there is potential of using the developed composites for insulation purposes.

\section{Introduction}

Nowadays, governments in developed countries demand engineering industries to implement ecosystem in their products and look for sustainable materials [1,2]. Material scientist and researchers are exploring the potential of using natural fibres as reinforcement in composites. Natural fibres have the advantages of availability, ease of manufacturing, and being less aggressive to manufacturing tools, sustainable, and biodegradable compared to the synthetic fibres [3-5]. There are many works that have been done to evaluate mechanical [5], physical [6], and tribological [7] behaviours of polymer composites based on natural fibres. In $[8,9]$, a comprehensive review on the flax fibres and the potential of using natural fibres in various engineering applications has been addressed. One of the recent applications of natural fibre polymeric composites is for energy absorption applications [10]. In civil engineering application, natural fibres have been used in different structures showing promising results [11].

The main concern in the composite characteristics is the bonding between the reinforcements and the matrix [12]. With regard to the natural fibres, there are poor adhesion properties between the raw natural fibres and the syntactic resin [13]. This is due to the presence of waxy layer on the surface of the fibres and undesirable substances. To overcome this issue, there are several chemical treatments that have been attempted to improve the interfacial adhesion of the fibres with the matrix. Silane and $\mathrm{NaOH}$ were found to be good chemical solutions at optimum concentration in which the surface of the fibres is dramatically enhanced resulting in high interfacial adhesion with the matrix [14]. $6 \% \mathrm{NaOH}$ solution removed the waxy layer of several natural fibres such as coir [15, 16], kenaf [17], and jute [18]. In addition, at this percentage of concentration, there is no damage on the structure of the fibres. However, at higher percent of $\mathrm{NaOH}$, there is significant damage to the fibres structure which deteriorated and the strength of the fibres [16].

Thermal characteristic of polymeric composites is one of the key components in materials selection especially in civil constructions. The thermal behaviour of polymers based on natural fibres has not been comprehensively understood and less works have been reported. Degradation of fibre polymer composites has been extensity studied. However, insulation behaviour of the composites is not fully reported and understood. Therefore, there is a need for investigating the insulation properties of fibre polymeric composites. 
In recent work by [19], hemp fibres have been used as natural reinforcements for polyester composites. The work showed that the addition of the hemp fibres in $20 \%$ caused significant improvement to the insulation performance of the polyester composites. In another work by [20], thermal conductivity of abaca fibre composites as a function of lumen and cell wall structure has been studied. The work showed that the abaca fibres also improved the insulation behaviour of the wall since the conductivity of the wall dropped when abaca fibres incorporated in the wall materials.

In the light of the above, this work is motivated to comprehensibly and experimentally understand the influence of natural fibres on thermal characteristics of polymeric composites. In the current study, sisal fibres reinforced epoxy composites were developed in two forms as untreated sisal fibres and treated. The thermal conductivity of the developed composites with different volume fractions of fibres was determined. Optimum volume fraction is identified from mechanical and thermal point of views.

\section{Methodology}

2.1. Material Selection and Preparation. Sisal fibres were obtained from India in raw form. The fibres were cleaned and combed with water. Some of the fibres were used to fabricate the untreated samples and some fibres were treated with $6 \% \mathrm{NaOH}$ concentration. In the treatment, the fibres were immersed in the solution for 24 hours and then washed with water. The fibres were then dried in an oven at temperature of $50^{\circ} \mathrm{C}$ for 24 hours. The fibres were cut into $15 \mathrm{~mm}$ in length. The samples were prepared using an open mould technique. A mould in dimensions of $100 \mathrm{~mm}$ length and $45 \mathrm{~mm}$ diameter was used in the fabrication. The inner surface of the mould was coated with waxy layer (mirror glaze) to ease the removal of the samples after the testing. Epoxy (ultra platinum) was used as a resin with a mixing rate of $50 \%$ with hardness. Different volume percent of fibres in the composites was considered as $0 \%-30 \%$.

2.2. Sample Preparation. In the fabrication procedure, the fibres were mixed with the mixture of the resin and the hardener and then poured into the mould. Vacuum process was applied to get rid of the air in the samples. The samples were kept in the mould for 24 hours for self-curing process. After that the samples were removed from the mould and placed in an oven at temperature of $80^{\circ} \mathrm{C}$ for 24 hours. The samples were taken out and numbered. The samples were drilled from the surface to the centre of the composite bar. There were four holes drilled in the sample and the distances between the holes were fixed to $20 \mathrm{~mm}$, Figure 1. M-Flex insulation pipe was used to insulate the bars of the samples. The bar of the samples was drilled precisely using automated drill machine from the surface to the centre of the sample. Holes were made on the insulator to insert the thermocouples to reach the centre of the samples. Type $\mathrm{K}$ thermocouple (chromel/constantan) was used in the experiments. The six thermocouples were attached to a reader to capture the temperature at each hole in the sample.

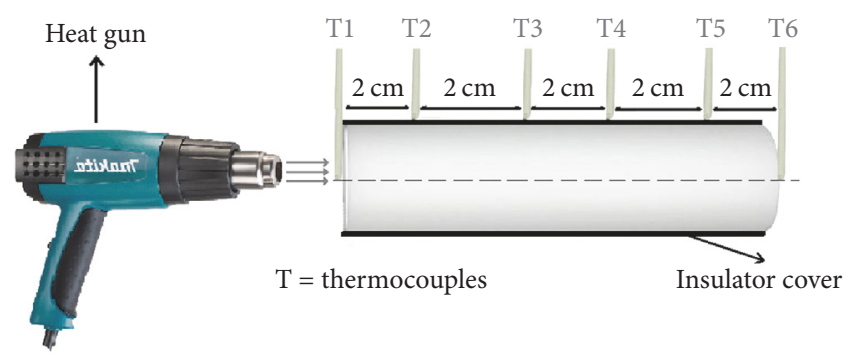

FIGURE 1: Thermal conductivity measurement.

2.3. Experimental Setup and Procedure. The experiments were conducted using convection method, ASTM D5930-17. The setup is shown in Figure 1. Basically, there is heat suppler to one end of the samples. The heat supplier was fixed to be $1 \mathrm{kw}$. Before starting the experiments, the samples were insulated and thermocouples were fixed in each hole with the free ends of the sample as well. One of the ends will be facing the heater and the second end will be free for cooling via the atmosphere. In the experimental procedure, the heater is switched on and the temperature values were captured every minute. Six values of temperature were captured each time and recoded with the time. The six temperatures captured are at the points illustrated in Figure 1. Temperature differences were calculated and the percent of the temperature reduction was calculated. This is with respect to the maximum temperature measured at the heated end of the sample. The temperature difference is determined for sample between the heated end and the first hole. The reduction percent is determined by dividing the temperature difference and the origin temperature at the heated end. The aim of the evaluation is to gain the maximum heat reduction with the consideration of the material performance.

\section{Results and Discussion}

The results of the experimental work are presented in two forms as temperature differences between two distances and the reduction percent which represents the insulation performance of the samples. The section is divided into two as untreated and treated composites.

\subsection{Thermal Characteristics of Untreated Sisal Fibre/Epoxy Composites. Temperature distribution in the sample of $10 \%$ untreated sisal fibre reinforced epoxy composites and the reduction in the temperature transfer is given in Figures 2(a) and 2(b), respectively. In Figure 2(a), it seems that the temperature increases with the time for all the five readings of the thermocouples. However, after 20 min of heating process, the temperature seems to be stabilised for all the sections in the samples which represents the steady state heat transfer condition. T1 represents the heated end of the sample and T6 is the free end of the sample which are exposed to the heater or air, respectively. T1 is the highest value of the temperature since it is exposed to the heater directly and T6 is the lowest since it is exposed to the cold end of the sample.}




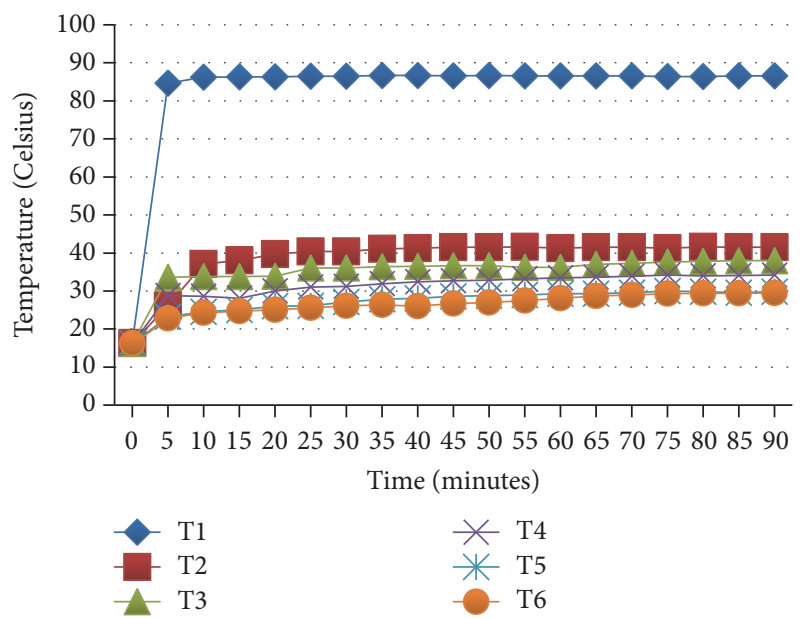

(a) $10 \%$ untreated fibre

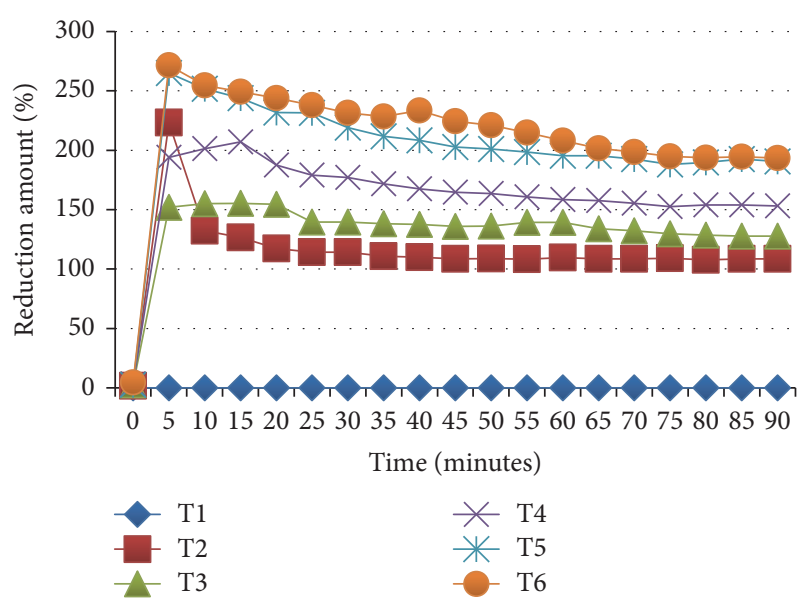

(b) $10 \%$ untreated fibre reduction

Figure 2: Temperature distribution in untreated $10 \%$ sisal/epoxy composites and reduction percent.

One can see that, with the distance of $10 \mathrm{~mm}$ from the heated end, there is great drop in the temperature from $\mathrm{T} 1$ to $\mathrm{T} 2$, that is, from $100^{\circ} \mathrm{C}$ to $40^{\circ} \mathrm{C}$. At further distance, the temperature dropped further to reach $25^{\circ} \mathrm{C}$ which is very close to the atmosphere temperature at distance of $50 \mathrm{~mm}$. Further increase in the distance did not show dramatically drop in the temperature. In other words, at the thickness of $50 \mathrm{~mm}$, high insulation performance can be achieved for this composites and can be considered the optimum thickness for the insulated component. Figure 2(b) shows the reduction percent in the temperature across the sample which represents the insulation rate at each distance with respect to the heated end. The highest insulation rate can be seen when the large thickness of the sample is used which is $100 \mathrm{~mm}$. At very small distance of $10 \mathrm{~mm}$, the reduction in the temperature is about $150 \%$. This is a very promising result for such composites.

With respect to the influence of the fibres mount in the sample, Figure 3 represents the thermal results of epoxy samples containing $20 \%$ of untreated sisal fibres. The trend of the temperature distribution insider the sample of $20 \%$ fibres

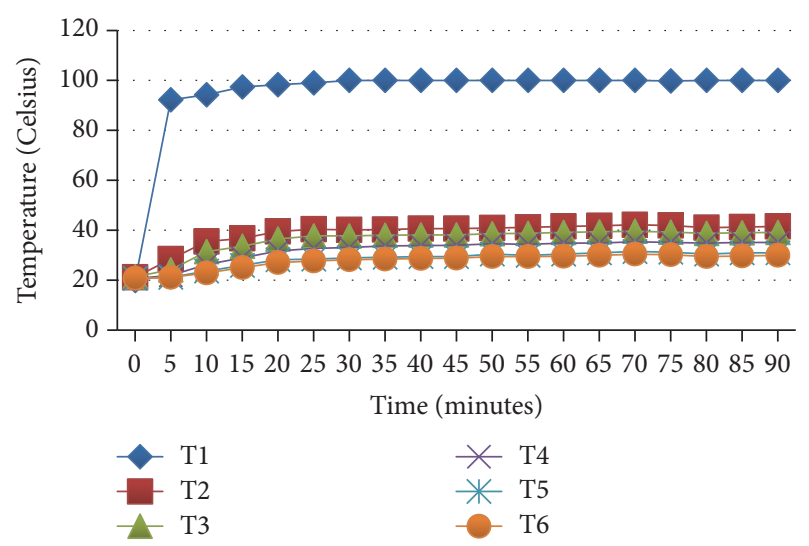

(a) $20 \%$ untreated fibre

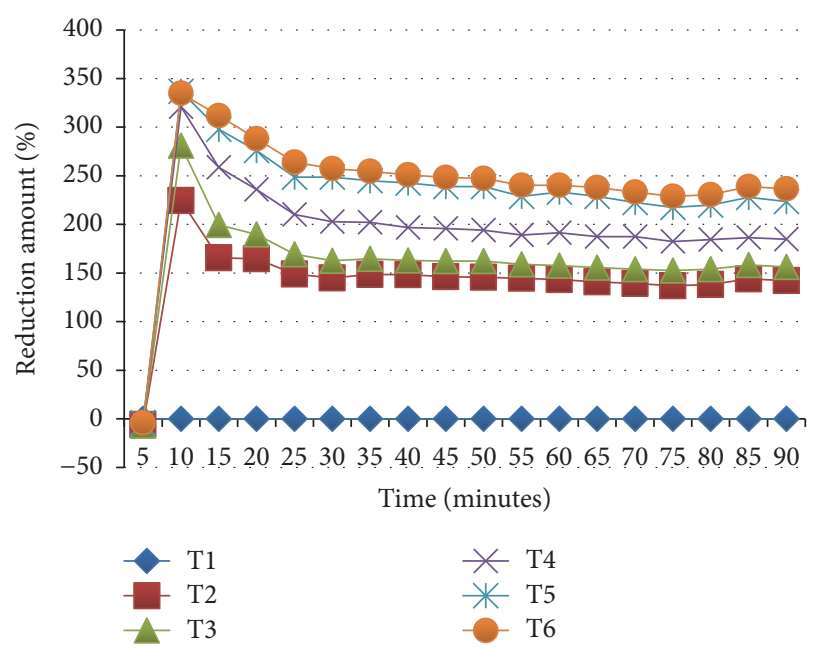

(b) $20 \%$ untreated fibre reduction

Figure 3: Temperature distribution in untreated 20\% sisal/epoxy composites and reduction percent.

is similar to the ones presented for the sample containing $10 \%$ of fibres. However, in terms of value, there is slight differences since the temperature is slightly dropped in the $20 \%$ of fibre compared to the one for the $10 \%$ of the fibre. To show the effect of the fibre content on the thermal behaviour of the composites, the result for the $30 \%$ fibre could show a clear differences in the following section.

For the $30 \%$ of sisal fibre/epoxy composite, the insulation performance is displayed in Figure 4 . The temperature distribution of in the sample is omitted since the trend is very similar to the ones presented for the $10 \%$ and $20 \%$ of sisal/epoxy composites. The figure shows that the insulation rate can reach up to $400 \%$ towards the end of the sample. At the same distance, the composites with the content of $10 \%$ fibres showed only $200 \%$ insulation rate as shown in Figure 2. In other words, the high content of the fibre increases the insulation rate of the composite. This is attributed to the fact that the natural fibres have some voids in its structure especially the untreated fibres [21,22]. The presence of the voids as air in materials increases the insulation rate as reported by $[23,24]$. In the case of the treated fibres, the 


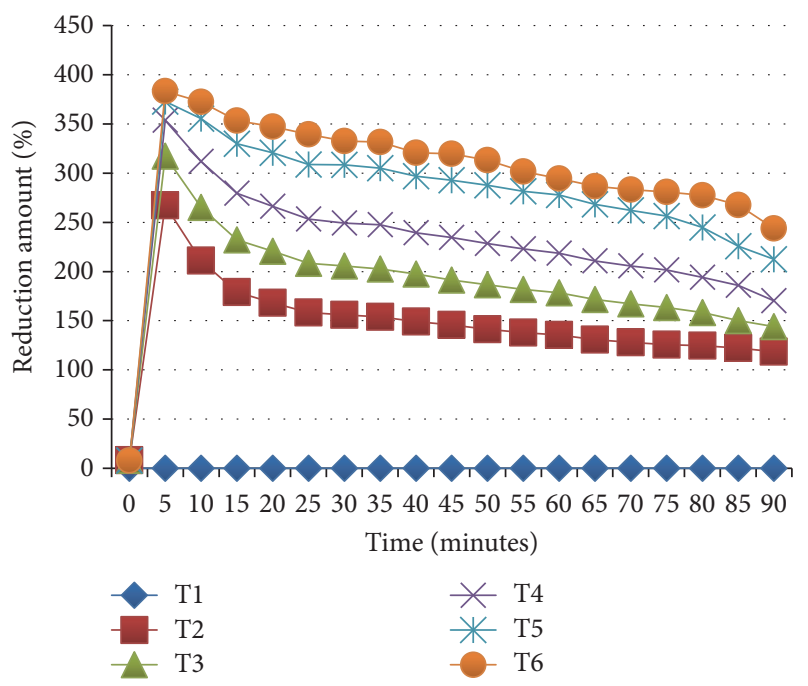

FIgURE 4: Temperature distribution in untreated 30\% sisal/epoxy composites and reduction percent.

outer layer removed due to the chemical treatment and the amount of void is expected to drop since during the curing the resin will enter the inner structure of the fires. This is very beneficial from mechanical point of view since it increases the interlock of the fibres in the bulk of the materials [5].

\subsection{Thermal Characteristics of Treated Sisal Fibre/Epoxy} Composites. The results of the treated sisal fibre reinforced epoxy with different contents of fibres (20\% and 30\%) are presented in Figure 5. The temperature distribution is in similar trends to the ones given for the untreated fibres. However, the values of the temperature were slightly higher since the insulation rate was slightly lower. The insulation rate of the treated fibres epoxy composites is displayed in Figure 5 showing that the values are about $300 \%$ and $275 \%$ for the $20 \%$ fibre and the $30 \%$ fibres, respectively. In previous section. The maximum insulation rate was exhibited for the untreated composites when the content of the fibres was 30\% since the insulation rate was about $400 \%$. In comparison to the treated fibre with the same content, it can be seen that the treatment of the fibres dropped the insulation rate from $400 \%$ to $275 \%$. This can be expected as explained previously. Treatment of the fibres allows the resin to enter the bundle of the fibres which makes the fibres very homogeneous and the amount of air in the composites would drop as well. The less amount of air in the composites is the main reason of the drop of the insulation rate of the composite. However, the literature recommended using the treated fibres since they have better support to the mechanical properties of the composites $[6,25]$.

\section{Morphology of Fractured Samples}

After the experiments have been conducted, the samples were fractured and small pieces of the samples in size of $10 \mathrm{~mm}^{3}$ were coated with thin layer of gold to conduct

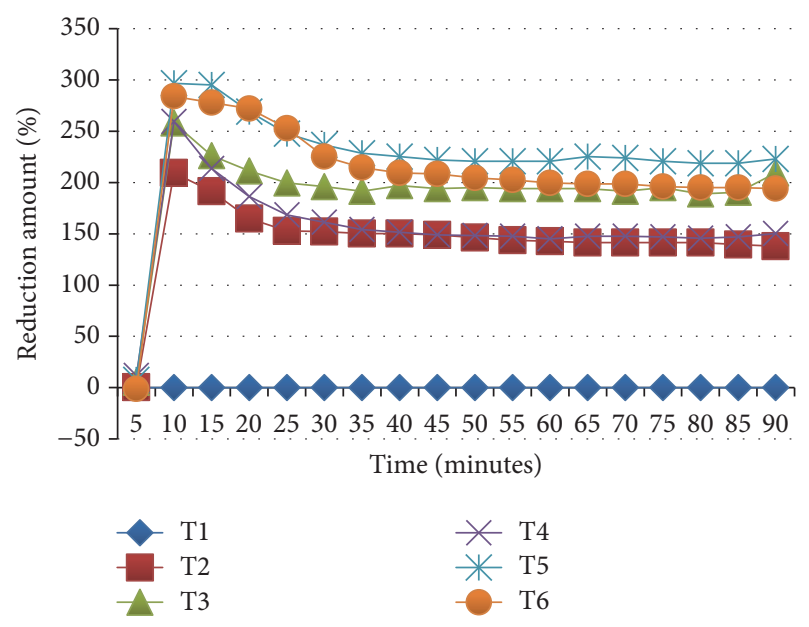

(a) $20 \%$ treated fibre reduction

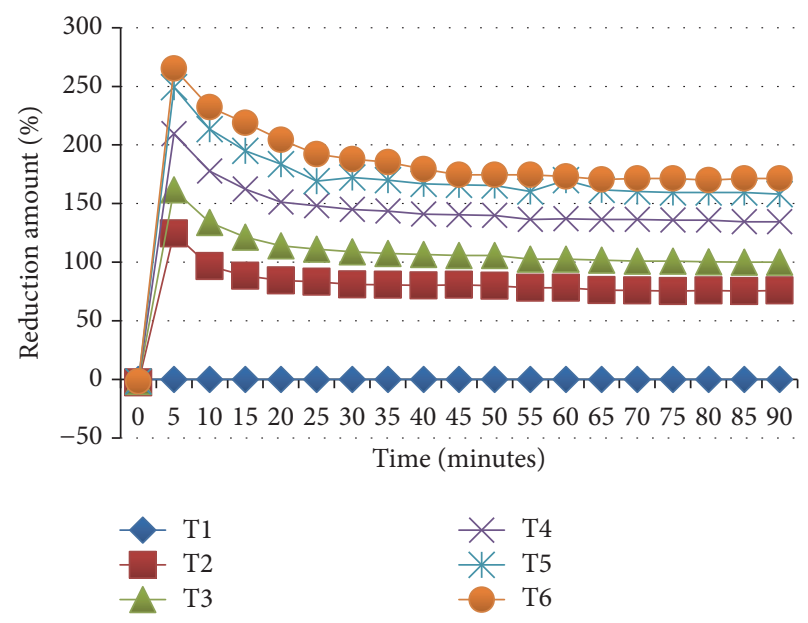

(b) $30 \%$ treated fibre reduction

FIGURE 5: Temperature distribution in untreated $20 \%$ sisal/epoxy composites and reduction percent.

the SEM observation using desktop Joel SEM. The micrographs of the composites are presented in Figure 6 for untreated and treated sisal fibre reinforced epoxy composites. In both micrographs and for both treated and untreated composites, a clear presence of voids is evidence. However, there is clear pull out of the untreated fibres which worsen the load transfer from the fibre with the matrix during the tensile or compressive loading conditions. With the case of the treated fibres, it seems the fibres were well adhered to the resin and no pull-out or detachments can be seen. This confirms the thought that treated fibres should be considered in the composites design despite the thermoresults that showed that the untreated fibres exhibited high insulation performance compared to the treated fibres.

\section{Conclusions}

The experimental data of the current study on the effect of volume fraction of treated and untreated fibres on the thermal 


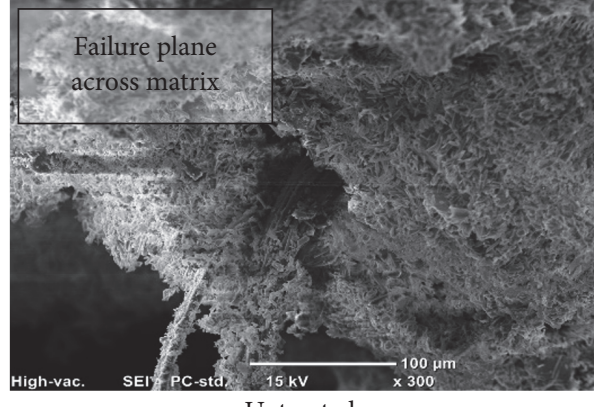

Untreated

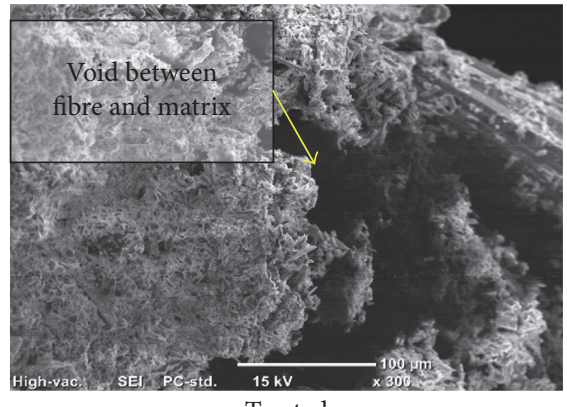

Treated

FIGURE 6: Micrographs of sisal fibre reinforced epoxy composites.

characteristics of epoxy composites was presented. The main findings of the work as follows:

(i) Sisal fibres significantly improved the insulation properties of epoxy composites since the natural fibres have the void generated inside the composites which acted as good insulator. More than 400\% insulation rate was achieved when untreated fibres were used.

(ii) The untreated fibres have better insulation rate to the epoxy composited compared to the treated fibres since the untreated fibres generated more air inside the composites compared to the treated one. However, this is not recommended since untreated fibres result in poor interfacial adhesion of the fibres with the matrix. This is confirmed with the aid of the SEM observation.

(iii) Increasing the volume fraction of the sisal fibres in epoxy composites increases the insulate rate which was due to the increase of air amount in the composites.

(iv) Treated fibres are recommended for the composites fabrication. However, further study is required to identify the optimum volume fraction of the sisal fibres from mechanical point of views.

\section{Conflicts of Interest}

The authors declare that they have no conflicts of interest.

\section{References}

[1] S. Sharma and I. Henriques, "Stakeholder influences on sustainability practices in the Canadian forest products industry," Strategic Management Journal, vol. 26, no. 2, pp. 159-180, 2005.

[2] M.-L. Tseng, A. S. F. Chiu, R. R. Tan, and A. B. SiribanManalang, "Sustainable consumption and production for Asia: sustainability through green design and practice," Journal of Cleaner Production, vol. 40, pp. 1-5, 2013.

[3] F. Ahmad, H. S. Choi, and M. K. Park, "A review: Natural fiber composites selection in view of mechanical, light weight, and economic properties," Macromolecular Materials and Engineering, vol. 300, no. 1, pp. 10-24, 2015.
[4] M. S. Huda, L. T. Drzal, D. Ray, A. K. Mohanty, and M. Mishra, "Natural-fiber composites in the automotive sector," Properties and Performance of Natural-Fibre Composites, pp. 221-268, 2008

[5] B. F. Yousif, A. Shalwan, C. W. Chin, and K. C. Ming, "Flexural properties of treated and untreated kenaf/epoxy composites," Materials \& Design, vol. 40, pp. 378-385, 2012.

[6] A. Shalwan and B. F. Yousif, "Influence of date palm fibre and graphite filler on mechanical and wear characteristics of epoxy composites," Materials \& Design, vol. 59, pp. 264-273, 2014.

[7] A. Shalwan and B. F. Yousif, "In state of art: mechanical and tribological behaviour of polymeric composites based on natural fibres," Materials \& Design, vol. 48, pp. 14-24, 2013.

[8] L. Yan, N. Chouw, and K. Jayaraman, "Flax fibre and its composites-a review," Composites Part B: Engineering, vol. 56, pp. 296-317, 2014.

[9] L. Yan, B. Kasal, and L. Huang, "A review of recent research on the use of cellulosic fibres, their fibre fabric reinforced cementitious, geo-polymer and polymer composites in civil engineering," Composites Part B: Engineering, vol. 92, pp. 94132, 2016.

[10] L. Yan and N. Chouw, "Crashworthiness characteristics of flax fibre reinforced epoxy tubes for energy absorption application," Materials \& Design, vol. 51, pp. 629-640, 2013.

[11] B. Yan, L. Huang, L. Yan, C. Gao, and B. Kasal, "Behavior of flax FRP tube encased recycled aggregate concrete with clay brick aggregate," Construction and Building Materials, vol. 136, pp. 265-276, 2017.

[12] P. K. Mallick, Fiber-Reinforced Composites: Materials, Manufacturing, and Design, CRC Press, 2007.

[13] D. B. Dittenber and H. V. S. Gangarao, "Critical review of recent publications on use of natural composites in infrastructure," Composites Part A: Applied Science and Manufacturing, vol. 43, no. 8, pp. 1419-1429, 2012.

[14] X. Li, L. G. Tabil, and S. Panigrahi, "Chemical treatments of natural fiber for use in natural fiber-reinforced composites: a review," Journal of Polymers and the Environment, vol. 15, no. 1, pp. 25-33, 2007.

[15] H. Gu, "Tensile behaviours of the coir fibre and related composites after $\mathrm{NaOH}$ treatment," Materials \& Design, vol. 30, no. 9, pp. 3931-3934, 2009.

[16] L. Yan, N. Chouw, and X. Yuan, "Improving the mechanical properties of natural fibre fabric reinforced epoxy composites by alkali treatment," Journal of Reinforced Plastics and Composites, vol. 31, no. 6, pp. 425-437, 2012. 
[17] A. M. M. Edeerozey, H. M. Akil, A. B. Azhar, and M. I. Z. Ariffin, "Chemical modification of kenaf fibers," Materials Letters, vol. 61, no. 10, pp. 2023-2025, 2007.

[18] L. Y. Mwaikambo and M. P. Ansell, "Chemical modification of hemp, sisal, jute, and kapok fibers by alkalization," Journal of Applied Polymer Science, vol. 84, no. 12, pp. 2222-2234, 2002.

[19] J. Zach, R. Slávik, and V. Novák, "Investigation of the Process of Heat Transfer in the Structure of Thermal Insulation Materials Based on Natural Fibres," in Proceedings of the International Conference on Ecology and new Building materials and products, ICEBMP 2016, pp. 352-359, Czech Republic, June 2016.

[20] K. Liu, Z. Yang, and H. Takagi, "Anisotropic thermal conductivity of unidirectional natural abaca fiber composites as a function of lumen and cell wall structure," Composite Structures, vol. 108, no. 1, pp. 987-991, 2014.

[21] M. M. Kabir, H. Wang, K. T. Lau, and F. Cardona, "Chemical treatments on plant-based natural fibre reinforced polymer composites: an overview," Composites Part B: Engineering, vol. 43, no. 7, pp. 2883-2892, 2012.

[22] P. J. Herrera-Franco and A. Valadez-González, "Mechanical properties of continuous natural fibre-reinforced polymer composites," Composites Part A: Applied Science and Manufacturing, vol. 35, no. 3, pp. 339-345, 2004.

[23] D. D. L. Chung, "Cement reinforced with short carbon fibers: a multifunctional material," Composites Part B: Engineering, vol. 31, no. 6-7, pp. 511-526, 2000.

[24] K. Ramamurthy, E. K. K. Nambiar, and G. I. S. Ranjani, "A classification of studies on properties of foam concrete," Cement and Concrete Composites, vol. 31, no. 6, pp. 388-396, 2009.

[25] Z. N. Azwa, B. F. Yousif, A. C. Manalo, and W. Karunasena, "A review on the degradability of polymeric composites based on natural fibres," Materials and Corrosion, vol. 47, pp. 424-442, 2013. 

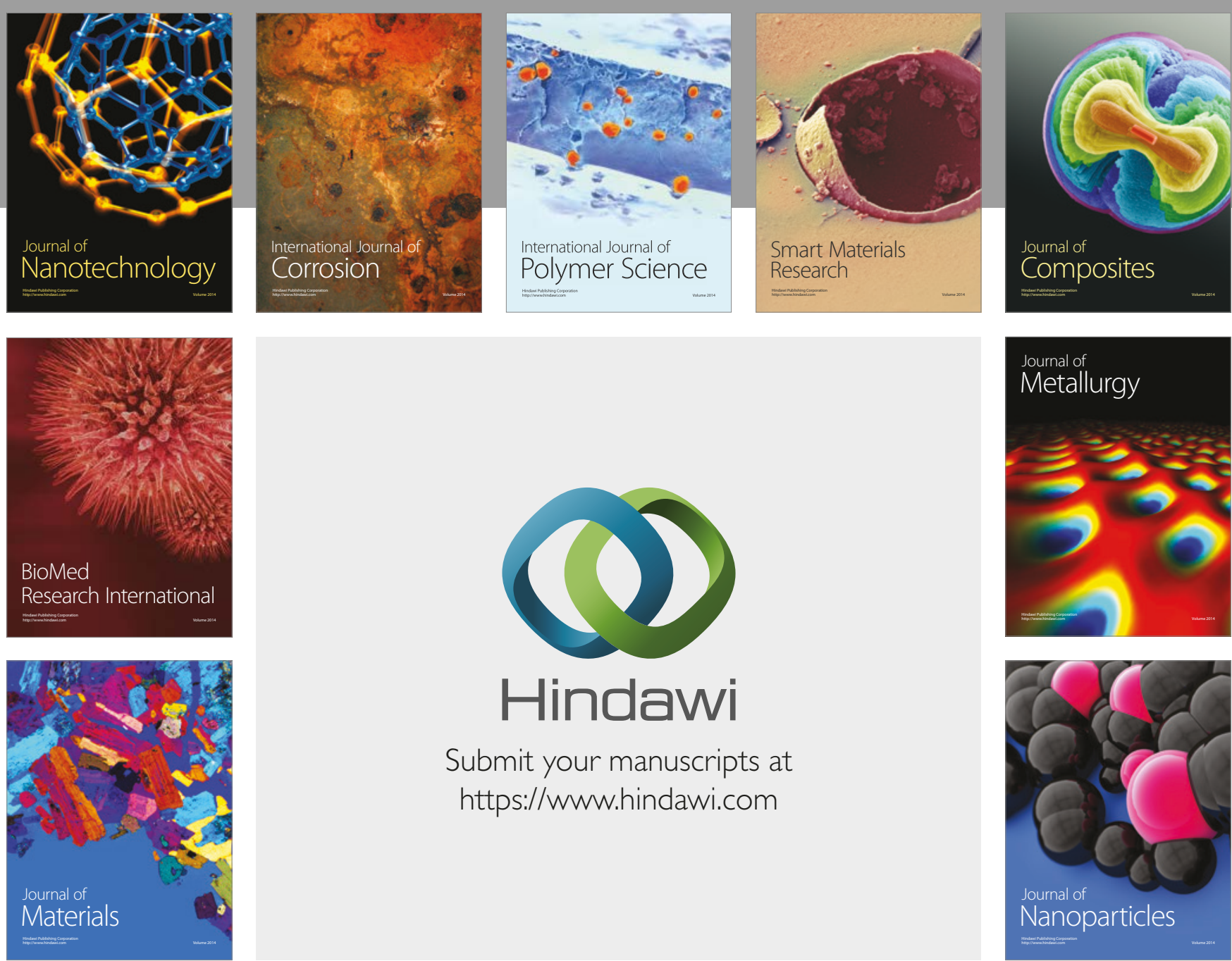

\section{Hindawi}

Submit your manuscripts at

https://www.hindawi.com
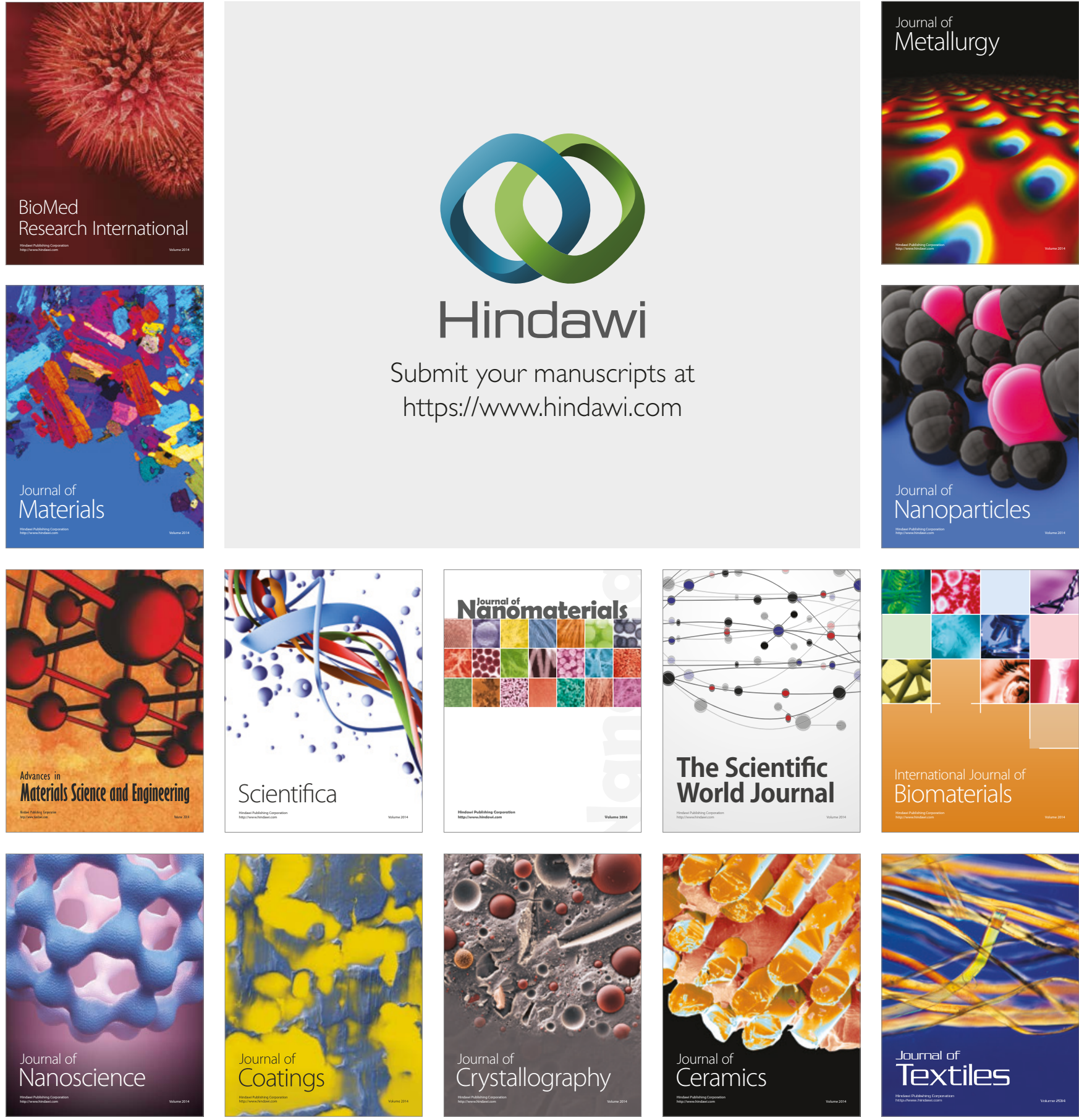

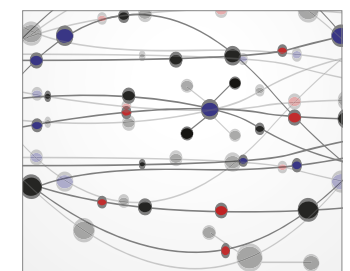

The Scientific World Journal
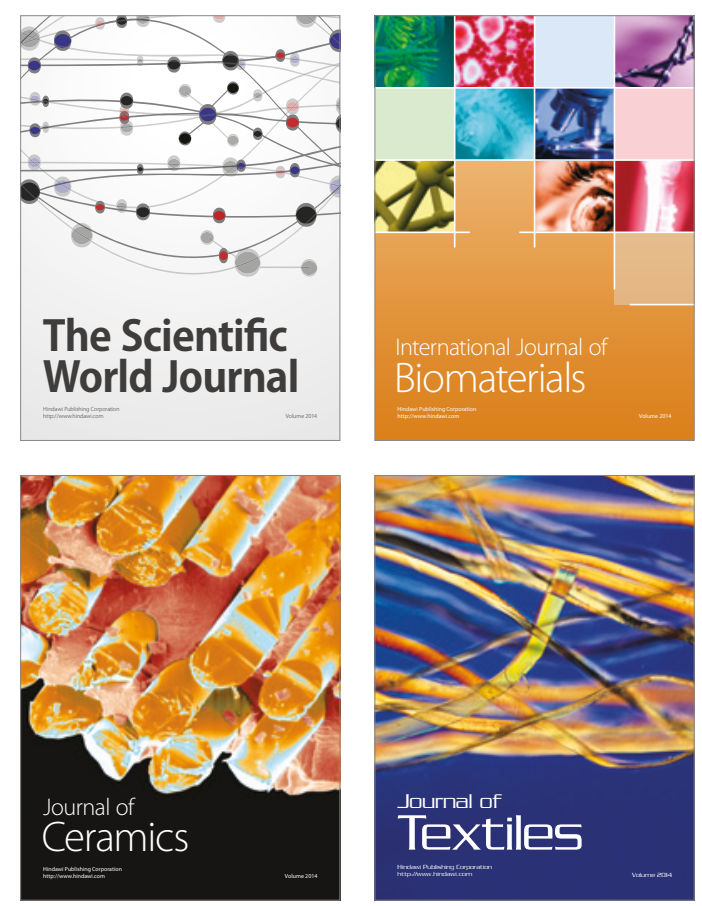